\title{
7 \\ Pilot fatigue and the regulation of airline schedules in post-war Britain
}

\author{
Natasha Feiner
}

\section{Introduction}

On 13 March 1954, a British Overseas Airways Corporation (BOAC) Lockheed Constellation aircraft crashed at Kallang Airport, Singapore. Part way through a scheduled flight from Sydney to London, the aircraft struck a seawall on approach to runway six. The undercarriage was damaged and the integral fuel tank was disrupted. When the aircraft touched down on the runway the starboard wing broke off and the undercarriage collapsed. The aircraft came to rest eighty yards from the seawall, in flames. A number of crew members, including Captain T. W. Hoyle, managed to escape the burning wreckage through a glass panel in the cockpit, but the main cabin door and emergency exits could not be opened. Though attempts were made to rescue passengers through holes cut into the fuselage, these were, as one report commented following the accident, 'almost completely unsuccessful.' ${ }^{1}$ Of the forty passengers and crew on board the aircraft, thirty-three were killed.

Following the accident, Singapore's Supreme Court conducted a public inquiry. On 16 November 1954 the inquiry commission published a forty-six-page report which detailed the causes and circumstances of the crash. The report drew attention to the undoubtedly long hours' worked by the crew and the limited availability of in-flight rest facilities. ${ }^{2}$ The crew, it was found, had worked for a total of twenty-one and a half hours and, while rest facilities were available, the inquiry 
commission deemed these inadequate. The Constellation aircraft was not equipped with bunks and crew were required to rest instead on a mattress 'placed over the luggage.' The authors of the report noted that it seemed 'unlikely' this provided 'a very comfortable resting place. ${ }^{3}$ The report concluded that insidious fatigue might have affected Captain Hoyle's judgement in the last stages of the approach to landing. As the Singapore Free Press explained following the report's publication:

The fact that his first point of touch down came closer to the threshold markings (at the seawall end of the runway) than he originally intended can probably be attributed to a degree of tiredness which he may or may not have been aware. ${ }^{4}$

Given the possibility that 'tiredness' might have affected Hoyle's performance and, in turn, caused the accident, the report published by Singapore's Supreme Court made two recommendations on the subject of crew fatigue: first, that crew fatigue be scientifically investigated; and, second, that the regulations controlling pilots' hours of work and rest be reviewed.

Though it is an international industry, in the twentieth century civil aviation was governed almost entirely by national regulations. ${ }^{5}$ It was not, therefore, within the remit of Singapore's inquiry commission to produce directives in relation to the working practices of flight deck crew employed by British airlines. The recommendations outlined by the commission did, however, receive wide attention in Britain. In the days immediately following the report's publication a number of aviation associations in Britain publicly called for a review of pilots' hours of duty, in line with the recommendations of the Kallang inquiry. On 20 November 1954 Denis Follows, General Secretary of the British Airline Pilots Association (BALPA), penned an article for The Times in which he called for the introduction of a 'broad policy for maximum hours of duty for pilots' on a 'national scale.' 'The public has a right', Follows began, 'to expect that, whatever else may be the hazards of air travel, at least those which can definitely be eliminated by straightforward ministerial regulation should not be allowed to persist.' Since the close of the Second World War, he argued, commercial air transport had changed considerably. The 'social legislation', as Follows put it, that controlled the work and rest of pilots needed to be updated to reflect these changes. ${ }^{6}$ It was important, he concluded, that long hours of 
continuous duty - the apparent cause of the Kallang crash - were limited wherever possible.

At the time of the 1954 accident, there were no statutory limitations governing flight times in Britain. The regulations that did exist were not obligatory, and laid the responsibility for establishing flight time limitations on operators. ${ }^{7}$ The 1954 Air Navigation Order (ANO) required only that airlines produced flight time limitations in conformity with the permissive recommendations of the International Civil Aviation Organization (ICAO), which required simply that flight time limitations of some sort 'should be established such as to ensure safety.' Airlines interpreted this rule in various ways, but in most cases imposed an upper limit on the number of hours pilots were permitted to fly in a month, in line with the principle of the operational limit employed by the Royal Air Force (RAF) during the Second World War. ${ }^{9}$

The Kallang crash was only one of many instances that called into question the safety of pilots' working practices in the 1950s. One year earlier a York aircraft en route from the Azores to Gander, Canada, crashed under similar circumstances. The accident report, published in January 1954, attributed the cause of the crash to pilot fatigue. It was found that the flight deck crew had worked continuously for twentythree hours and, as such, the accident report recommended that 'the whole subject of crew fatigue [should] receive study. ${ }^{10}$ Prompted by this report, and increased public interest in flight safety following the air crash in Kallang, in the mid-1950s pilots' hours of work and rest were reviewed by national agencies, and in 1957 a new regulatory framework was introduced to control pilots' schedules.

Based on a model of fatigue that had its roots in the late nineteenth century, the concept of balance was implicit in these regulations from the outset. The notion of fatigue was vague and contested throughout the twentieth century. Attempts to find a biological marker for fatigue had failed, but by the mid-twentieth century there was broad agreement among researchers that fatigue was the result of bodily or psychological imbalance. In 1936 Howard E. Collier (1890-1953), a reader in Industrial Hygiene at the University of Birmingham, described fatigue as a state of "unbalance.. ${ }^{11}$ For Collier, fatigue occurred as a result of an 'absence of harmony' between 'the organism and its environment or between the various subordinate parts within the organism itself' or, more basically, between 'intake and output. ${ }^{12}$ Two decades later, 
physiologists based at the University of Leeds described fatigue in similar terms: as failure to maintain physiological 'equilibrium. ${ }^{13}$ In 1945 Adolphe Abrahams (1883-1967), a physician now considered the founder of British sports science, attributed chronic fatigue to an imbalance between work, rest and social activities. ${ }^{14}$ Though opinion differed on the precise causes and manifestations of fatigue in humans, it was widely agreed by the middle decades of the twentieth century that if the dynamic equilibrium of the body was upset - by ill health, emotional stress or intensive working practices - fatigue would result. The notion that an imbalance of work and leisure time might cause fatigue (or what later became known as 'burnout') became increasingly commonplace as the twentieth century progressed. As these ideas spread, they shaped new norms about work, on the one hand, and 'life' (comprising all the activities pursued without financial reward, including education, leisure and consumption), on the other. In turn, these new norms informed and influenced the regulation of work and rest.

With a particular focus on post-war civil aviation, this chapter outlines how and why airline schedules were regulated in the post-war period. Though there were some attempts to harmonise regulations across Europe from the 1990s, full integration of flight time limitations in Europe by the European Aviation Safety Agency (EASA) only came to pass in February 2016. ${ }^{15}$ The focus here is on national, rather than intergovernmental, regulation. Specifically, this chapter traces how the relationship between the British state, business and individual workers shifted in regulatory terms between 1954 and 1982, a period of significant political change, with state interventionism being replaced, by the 1980s, with widespread faith in market mechanisms and a retrenchment of the state under the Conservative governments of Margaret Thatcher. The chapter argues, however, that existing historiographical assumptions need to be re-evaluated. Though there are many examples of state interventionism in the post-war period, the picture is more complex than sometimes assumed. In the second half of the twentieth century, British governments consistently refused to formally control airline schedules. ${ }^{16}$ Regulation and enforcement was, throughout the century, permissive and flexible. In order to highlight this complexity, the chapter traces three interconnected but distinct concepts through the post-war period: fatigue, the state and the self. Speaking to some of the core themes of this volume, it asks how and why new selves were 
constructed and regulated in the post-war period at the expense of structural adjustments to working environments, sets out a new timeline for twentieth-century subjectivity and historicises present-day concerns with work-life balance and the costs of overwork. ${ }^{17}$

Acute fatigue and the regulation of working hours, 1954-72

In the twentieth century overwork was under-regulated. In fact, many workers in post-war Britain were encouraged to stay on the job beyond their contracted working hours. Overwork, and the fatigue that this often entailed, were generally accepted where financial recompense was offered. There were, however, some instances where overwork was formally restricted. In the United Kingdon, regulations governing hours of work and rest stretch back to the nineteenth century. Many state regulations - including the 1844 and 1850 Factory Acts - had a social and moral imperative. They were intended to protect vulnerable groups from exploitation and to safeguard the health of workers. ${ }^{18}$ From the early twentieth century, employers increasingly introduced more detailed regulations relating to working hours and rest periods, particularly for factory workers. ${ }^{19}$ These regulations were often based on research produced by wartime and interwar research committees, such as the Health of Munition Workers Committee (HMWC) and the Industrial Fatigue Research Board (IFRB) ${ }^{20}$ Workplace and laboratory studies carried out by these committees indicated that 'productivity was closely related to the health of the workers', and that longer hours - if these caused fatigue and ill health - did not necessarily entail greater output. ${ }^{21}$

Much useful historical literature has explored the regulation of work and rest in factory settings, but fatigue was also experienced and managed beyond the factory. ${ }^{22}$ In nineteenth- and twentieth-century Britain fatigue was endemic in a number of industries, particularly those that required round-the-clock work, such as transportation, construction, agriculture, healthcare and other public services. ${ }^{23}$ The regulation of working hours in these industries was inconsistent. For some, such as railway workers, hours of work had been controlled since the late nineteenth century. ${ }^{24}$ For many others, though, there was no industry-specific regulation of work and rest. This trend was not specific to Britain. On the other side of the Atlantic, working hours were only regulated beyond the factory in certain circumstances. Alan Derickson 
has argued that working time regulation was limited to industries where 'sleeplessness posed a threat to the general welfare. ${ }^{25}$ In other words, working hours were controlled only in industries that were high risk where the margin for human error was slim, and the results of error potentially catastrophic - and high responsibility - where the general public was likely to be involved or affected. In the twentieth century, American federal legislation was introduced to control the work and rest of train operators, long-haul truckers and commercial pilots. In some instances, further legislation was enacted on a state level. For example, in the 1980s New York State introduced restrictions on the number of hours postgraduate medical trainees could work. ${ }^{26}$ In the post-war period the British government imposed comparable limitations on professional drivers and commercial aircrew.

As described above, detailed regulations governing pilots' hours of work were first introduced in the mid-1950s following a series of accidents that were attributed, in part, to crew fatigue. The regulations in place at that time were not obligatory, and laid the responsibility for establishing flight time limitations on operators. ${ }^{27}$ The 1954 ANO simply required that airlines produced flight time limitations in conformity with the permissive recommendations of the ICAO: that limitations 'should be established such as to ensure safety. ${ }^{28}$ There was no specific guidance relating to maximum working hours and, given the long hours worked by the crews of the York in 1953 and the Constellation aircraft in 1954, the Ministry of Aviation felt it was important that the current system be re-examined. The Working Party on Operating Crew Fatigue and Flight Time Limitations (hereafter referred to as the Bowhill Working Party) was established to this end. Sir Frederick Bowhill (1880-1960), a well-known military figure who had acted as Commander-in-Chief of Coastal Command and later Transport Command during the Second World War, led the Working Party. Bowhill was joined by four others: E. A. Armstrong, the most experienced of the group in matters of civil aviation, had led the Civil Aviation Safety Group since 1953; Group Captain J. B. Veal and D. L. R. Halliday, formerly of the RAF; and Air Commodore J. D. Leahy, a medical officer at the Ministry of Transport. ${ }^{29}$ The expertise of the Working Party was heavily weighted towards military flight. Though most of its members had some experience of civil aviation from a managerial or medical perspective, none had first-hand experience of operating commercial 
aircraft. This fact would influence the perspective, and subsequent recommendations, of the Working Party.

Unlike the industrial fatigue committees operating in the first half of the twentieth century, the Bowhill Working Party was not involved in the collection of original laboratory or observational data. No investigations were commissioned by the Working Party in either laboratories, simulators or operational aircraft. Instead, like the wartime surveys of flying stress and psychological disorder undertaken by the Flying Personnel Research Committee (FPRC), fatigue and its management were framed in terms of subjective opinion. The Bowhill Working Party consulted a number of medical specialists, all of whom agreed that fatigue could 'contribute to accidents. ${ }^{30}$ There was, however, no medical consensus on the apparent causes or physical manifestations of fatigue, so the Working Party chose to rely instead on evidence supplied by airlines and trade unions. Given this evidence base, economic, safety and social - rather than medical - concerns shaped the Working Party's understanding of aircrew fatigue.

The opinions of airlines and trade unions did not coincide. Operators argued that no more regulations were necessary or required, while trade unions made the case for specific statutory limits. The Bowhill Working Party recognised that neither operators nor trade unions considered the matter 'from an entirely fatigue point of view' - other matters were consistently brought up by both sides. As Bowhill noted after meeting with both parties in September 1954, 'the questions of operations, schedules, etc. loom very largely into the picture'. In this respect, he noted, operators had 'a dual capacity, one for the good of their aircrew and one for their good name', while trade unions were 'out to improve the conditions of the aircrew. ${ }^{31}$ Fatigue could not, as Bowhill's notes make clear, be considered in isolation as it related directly to issues of scheduling, working hours, rest time and time off. In other words, the financial, safety and social aspects of operating crew fatigue were inextricably linked. Apparent tensions between economic and safety considerations formed an important part of the Bowhill Working Party's final report, which concluded that:

Any consideration of flight time limitations requires careful attention to be paid to the economic consequences. Every addition to the minimum operating crew of an aircraft means less pay load. Every additional stop 
to enable crew to rest may mean adding to an operator's crew strength or slowing down a schedule. Bearing in mind the highly competitive nature of international air transport it will be necessary when determining limitations which ensure adequate safety standards to ensure that an operator's ability to compete successfully is not necessarily impaired. ${ }^{32}$

Though safety was paramount, for the Bowhill Working Party it was important that airlines were not financially 'impaired' by strict legislation. ${ }^{33}$

The Bowhill Working Party privileged the concerns of operators. Economic considerations were, its members believed, of greatest importance, and the apparent threat that flying fatigue posed to air safety was given little weight. Trade unions, the Working Party thought, had overstated the problems associated with pilot fatigue in order to justify their social aims. In December 1954 Britain's largest aviation union, BALPA, had submitted a memorandum to the Working Party in which it called for specific and detailed legislation to limit the working hours of pilots and to balance pilot workload within and between rosters. BALPA argued that the pattern of operations common in the post-war world - which included night-time and early morning flights - induced fatigue and had serious implications for flight safety. In previous decades, when operations had been limited to daytime, pilots were, the union reasoned, naturally protected against fatigue:

This operational pattern had the effect of regulating to some extent the maximum hours of duty for the crews on the night-stopping services, but it had additionally an effect on the through services since it maintained the concept that the human body was pathologically designed to rest for a spell of some eight hours during darkness: hence the through services were run with the minimum violation of this then accepted rhythm and pilots were not usually required to sacrifice their rest during the hours of darkness more than on one occasion at a time. ${ }^{34}$

The turn to twenty-four-hour operations in the 1950s, BALPA concluded, had removed this 'natural protection' against fatigue. ${ }^{35}$ The Bowhill Working Party, however, was not convinced by this argument. Its final report concluded that the union's allegations were 'unsubstantiated' and that there appeared to be 'truth to the operators' suggestion that the unions' object in making these allegations [was] to further their aim of using the problem of fatigue to achieve an industrial end: ${ }^{36}$ 
These suspicions added weight to the Bowhill Working Party's position on working time regulation. In line with operators, the Working Party's members located responsibility for the management of fatigue with pilots, rather than with airlines or external agencies. 'There appears to be', Bowhill recorded following a meeting with airlines and trade unions in September 1954, 'a tendency to take away certain responsibilities from the captain of the aircraft and replace this by legislation.' 'Surely', he concluded, 'this is a wrong attitude.' For Bowhill, the captain of the aircraft 'must be responsible for the safety of his aircraft and in this safety factor fatigue must always be predominantly in his mind'. Though BALPA representatives had argued that pilots might be influenced 'by fear of [their] owners' or by 'being paid more' to continue work, after meeting with operators Bowhill decided that these positions 'very rarely, if ever' arose. ${ }^{37}$ In the view of the Bowhill Working Party, then, responsibility for flight safety lay with the pilot. Pilots, the Working Party argued, should be able to demonstrate self-awareness and control. Like the mid-century explorers described in Chapter 8, pilots were expected to be conscious of their energy levels and able to self-manage fatigue in flight if necessary. Reflecting broader contemporary concerns about professional autonomy and masculine self-discipline, the Bowhill Working Party argued that pilots should not be divested of this responsibility by way of legislation. ${ }^{38}$ This argument was predicated on a particular image of the post-war pilot. Pilots were, the Bowhill Working Party thought, trusted and skilled executives for whom professional autonomy was important. In this framework, pilots were envisioned as self-aware and self-sufficient, expected to be alert to mental and bodily changes and active in the management of fatigue. ${ }^{39}$

The reluctance of the Bowhill Working Party to impose strict limitations on pilots' hours of work and rest speaks to the uneasy relationship between the British state and industry in the post-war period. The immediate post-war years saw support for collectivist ideas and policies, the nationalisation of major industries, the birth of the National Health Service and economic management by the state. ${ }^{40}$ Following the return of the Conservatives into government in 1951, though, this collectivist advance was stemmed. ${ }^{41}$ High levels of public spending and taxation remained, but the idea of state intervention in economic and industrial matters was not universally popular. ${ }^{42}$

The Bowhill Working Party was uneasy about intervening in the operation of airlines but, given the apparent dangers of pilot fatigue, 
recommended that some limitations on flying hours should be introduced. Following the wartime RAF precedent, the report of the Working Party proposed that operators should set quantitative limitations on flying times to ensure that aircrews did not suffer from fatigue. ${ }^{43}$ Operators, the Working Party suggested, should set these limits themselves. Although the Bowhill Working Party did not think operators should be left with too 'much discretion on a subject in which the effect on airline costs may come into conflict with safety requirements', it concluded that only operators were in a position to 'assess satisfactorily the nature and effects of the work falling on ... [their] operating crews. ${ }^{44}$ Based on the premise that fatigue was a short-term reaction to imbalanced working practices in a single day, the regulation of daily working hours was recommended above all else. The nature of civil flying in 1950s Britain - long hours of work followed by long hours of rest - caused, according to the Bowhill Working Party, acute rather than 'cumulative' fatigue. ${ }^{45}$ As such, the Working Party's final report recommended that a daily limit on the number of hours pilots could work was the single most important countermeasure to fatigue. The report recommended a daily maximum of sixteen hours, but suggested that this could be extended to twenty-four consecutive hours 'to provide operators with reasonable flexibility in respect of slipping and rostering. ${ }^{46}$ Economic considerations, then, continued to loom large.

The recommendations of the Working Party formed the basis of a new ANO, which came into effect on 1 May $1957 .{ }^{47}$ The regulations contained in the ANO 'fell far short' of trade union expectations. ${ }^{48}$ BALPA argued that there was still 'too much discretion' for operators and that 'excessive flying' was still 'legally possible." ${ }^{49}$ Under the new ANO, long hours of work were still allowed in a single day. The flexible nature of the daily limit, BALPA representatives contended, entirely negated its existence. In addition, intensive and imbalanced rosters were not outlawed under the new ANO. No regulations were introduced in respect of rest periods and time off, as the Bowhill Working Party deemed these already adequate. As a result, BALPA argued that there was nothing to stop 'astute operators' exploiting 'loop-holes' to create intensive and imbalanced schedules. ${ }^{50}$

The regulations introduced by the Ministry of Transport in the 1950s set the tone for subsequent regulation of aircrew schedules. As in the 1957 ANO, later regulations tended to be permissive - to allow airlines discretion in terms of their implementation - to place the burden of 
responsibility for fatigue management on workers, and to conceptualise fatigue as a short-term rather than cumulative problem. This approach to flight time regulation was first challenged in the 1970s when, in response to growing concerns about the relationship between pilot workload and flight safety, the recently established Civil Aviation Authority (CAA) introduced new regulations that intended to balance the work and rest of pilots both within and between rosters, a framework that remained largely unchanged for almost half a century.

\section{Cumulative fatigue and the balanced duty cycle, 1972-75}

The 1970s marked a new, and increasingly complex, regulatory phase in Britain. While New Right ideologies gained momentum politically, in the same decade the most detailed statutory health and safety regulations to date were introduced under the 1974 Health and Safety at Work Act (HSWA). ${ }^{51}$ Though more detailed and expansive than any prior regulatory framework, the HSWA constituted, as Christopher Sirrs has pointed out, an uncomfortable compromise between interventionism and voluntarism. ${ }^{52}$ Premised on the ideal of self-regulation by industry, the HSWA situated the responsibility for workers' health outside the state, with employers and workers themselves. ${ }^{53}$ The Act was intended to alleviate the need for piecemeal and industry-specific regulation, but it did not provide universal protections. Transport workers were explicitly excluded from coverage: transport safety was deemed too 'large' and 'difficult' an area to legislate on, so even after the introduction of the HSWA the transport sector was governed by industry-specific regulations. ${ }^{54}$ Civil aviation, although not directly included under the purview of the HSWA, was influenced by the anti-legislative and selfregulatory sentiments contained in the 1974 Act, and the 1972 report on which it was based. This section sets out changes to the regulatory landscape of commercial flight in 1970s Britain. It will show that, though premised on new understandings of fatigue and pilot responsibility, the regulations introduced to minimise fatigue in 1975 marked a shift in principle rather than in practice.

As in the immediate post-war period, fatal accidents again prompted regulatory review of pilots' working practices. It was commonly acknowledged by contemporary commentators that 1972 was a bad year for the aviation industry. It was an especially bad year for air 
crashes: worldwide over 1,700 passengers and crew died in the space of twelve months. ${ }^{55}$ The most widely reported accident in Britain, the Staines air disaster, killed 118 people. It was, by far, the worst ever accident in British aviation history. The Air Accidents Investigation Branch (AAIB) concluded following a public inquiry that the incident occurred as a result of poor crew coordination and pilot error caused by an 'abnormal heart condition. ${ }^{56}$ As in 1954, though, the British media focused on other issues. Much was made, for example, of the conditions of work commonly experienced by British European Airways (BEA) pilots prior to the accident. In November 1972, The Times published an article detailing the complaints made by Captain Stanley Key before his death. In the weeks preceding the incident, Key complained to others about the length of his working days and his 'lack of free weekends. ${ }^{57}$ The Staines air disaster was never formally attributed to fatigue, but the wide publicity afforded to Key's complaints following the crash raised concerns about pilot workload and morale, and flight safety that the CAA was keen to address.

The Bader Committee was established in response to these concerns. It was composed of six members: Group Captain Douglas Bader (1910-82), former military pilot, member of the CAA and chairman; Dr Walter Tye, expert in aviation medicine, member of the CAA, and deputy chairman; John R. Sidebotham, an operations director of a British airline; Laurie Taylor, a senior airline captain and BALPA representative; and Norman A. White and Michael Varley of the CAA. ${ }^{58}$ The composition of the Committee was markedly different from that of the Bowhill Working Party two decades earlier. Some of its members had military backgrounds, but as a whole the Bader Committee had significant experience of commercial aviation. While the Bowhill Working Party made suggestions from outside the industry, the Bader Committee had relevant and varied expertise in matters of civil aviation and actively sought to co-create regulation with workers and airlines.

Though different in composition, the Bader Committee adopted a similar research strategy to its predecessor. Like the Bowhill Working Party, the Bader Committee disparaged medical and psychological models and measures of fatigue. Ambiguous and often only indirect, the medical offering was, in the Committee's view, not 'satisfactory'. On this basis the Committee concluded that 'assessment of fatigue' could only be undertaken subjectively. ${ }^{59}$ This entailed the exclusion of 
evidence relating to circadian 'desynchronization. ${ }^{60}$ Tacitly recognised for centuries, the cyclical functions of the body were increasingly investigated in the twentieth century. ${ }^{61}$ Extensive animal studies, and later experiments on humans in laboratories and workplaces confirmed early assumptions about biological periodicity. ${ }^{62}$ Human and animal life, it was found, biologically oscillated over hours, days and weeks. No consensus existed on the precise mechanisms involved in the mediation of biological rhythms until later in the twentieth century, but by the early 1970s it was widely agreed that hormones excreted by the pineal gland played a role in synchronising biological rhythms. Though wellestablished anecdotally by the 1960 s, medical discussion of circadian disruption in aircrew only began in earnest in the mid-1970s, after the Bader Committee had completed its regulatory review. ${ }^{63}$ Medical and scientific models of biological rhythmicity did not inform the perspective or subsequent recommendations of the Bader Committee.

Like the Bowhill Working Party two decades earlier, the Bader Committee framed fatigue in terms of personal experience. Committee members collected the opinions of over 200 contributors - including medical experts, trade unions, airlines and flight deck crew - before publishing its final report in June 1973. The report recommended that existing legislation was simplified. The Committee admitted that, despite its collective knowledge and experience, members had difficulty 'disentangling the interconnected mass of rules, law, directions and guidance' about flight time limitations and the prevention of pilot fatigue. ${ }^{64}$ The picture was, indeed, complex. By 1972 British civil aviation was subject to a number of national and international obligations. As a signatory to the Convention on International Civil Aviation held in Chicago in 1944, the UK had an obligation to comply with the international standards and recommended practices in the various annexes to the convention. The Bader Committee identified one annex that was particularly relevant to fatigue and flight time limitations Annex 6, Part 1, 'The Operations of Aircraft', which stated that:

An operator shall formulate rules limiting the flight time and flight duty periods of flight crew members. These rules shall also make provision for adequate rest periods and shall be such as to ensure that fatigue, occurring either in a flight or successive flights ... does not endanger the safety of the flight. ${ }^{65}$ 
Table 7.1: The basic limiting of flying duty periods for scheduling purposes, Report of the Committee on Flight Time Limitations, p. 8

Crew

ANO limit

Air Operators'

Certificate limit

1 pilot

2 pilots

2 pilots and 1 flight navigator

$2+$ pilots

$2+$ pilots with sufficient bunks for

in-flight rest

10

12

13

15

18

The guidance in Annex 6 was general in nature and did not provide any numerical values for rest or duty periods. A number of national requirements did, however, lay down explicit limitations on flying time, although these rarely matched up. There were, for example, disparities between the limits proposed by the 1972 ANO and the guidance material contained in the 1966 Air Operators' Certificate (see Table 7.1). Operators interpreted these guidelines inconsistently, and often set different internal limits on flying hours to those laid down by law as a result of industrial agreements with trade unions. There was also significant variation between airlines. Some airlines, such as BOAC, scheduled pilots right up to the legal 100-hour monthly limit, while others, such as BEA, imposed much more restrictive limits. Existing measures for the prevention of aircrew fatigue were, the Bader Committee concluded, complicated and disjointed. The Committee recommended that a new system of rules was introduced, 'preferably in one document', that simplified and clarified the limitations. ${ }^{66}$

Recommendations made by the Bader Committee were premised on the concept of a 'duty cycle' that included 'both duty and off-duty periods. ${ }^{67}$ The intention was to create a pattern of work for pilots 'akin to the normal manner of covering a like situation in other occupations and professions in industry and business. ${ }^{68}$ The model of work and rest common to office-based work - nine-to-five, Monday to Friday, with two days off at the weekend - offered workers, the Committee presumed, an appropriate work-life balance. Reflecting contemporary 
discussions about work-life balance, and the importance of home life for men as well as women, the Bader Committee argued that the 'home environment' was essential for the emotional health of pilots and was particularly important to mitigate the effects of personal stress 'leading to fatigue. ${ }^{69}$ Time at home had, the Bader Committee held, both physical and emotional benefits. To this end, pilot fatigue was transformed in regulatory discourse. Once framed in primarily physiological terms, by the 1970s the psychological and social pressures of commercial aviation were central to regulators' understanding of fatigue. ${ }^{70}$

In the early 1970s medical and social attitudes to work, and the emotional health of workers, were renegotiated. Moving away from strictly productivist arguments, a discourse of work-home interaction emerged that placed the health and well-being of the family centre stage. In this discourse the emotional health of workers was deemed important, not only for workplace safety and productivity, but also for the well-being of the nuclear family. 'When men are tired out', Michael Young and Peter Wilmott argued in 1973, 'they may bring home, if not the work itself, [then] some of its consequences. ${ }^{, 71}$ This, they suggested, had implications for the whole family. Medical practitioners were also concerned with the relationship between exhaustion and emotional resilience in this period. In 1974, German-born American psychologist Herbert J. Freudenberger (1926-99) conceptualised this as 'burnout. $^{72}$ These broader shifts in medical attitudes and social norms underpinned the recommendations of the Bader Committee. In its final report, the Committee suggested that proper attention be paid to the overall planning of the duty cycle and the time between consecutive duty cycles. This, the Committee argued, was the 'most appropriate framework for ... preventing fatigue. ${ }^{73}$ Marking a break with previous regulatory trends, the Bader Committee argued that balance across the whole duty cycle was a better antidote to crew fatigue than limitations on single duty periods. ${ }^{74}$

The regulatory framework proposed by the Bader Committee in 1973 was premised on an understanding of fatigue far removed from that discussed by the Bowhill Working Party two decades earlier. Drawing on anecdotal evidence from flight deck crew, the Bader Committee reconceptualised fatigue as a cumulative, rather than acute, problem. Though fatigue might sometimes be acute, it was, members thought, often compounded by difficulty sleeping. For the Bader 
Committee, fatigue became dangerous when pilots entered a cycle of acute fatigue and sleeplessness, often as a result of transmeridian travel. Though the Committee did not draw on the studies of circadian disruption carried out in laboratories and other workplaces since the 1960s, it did seek to recognise the problems associated with transoceanic travel - referred to as 'jet lag' by some - in its recommendations.

The Bader Committee suggested two solutions to the problem of aircrew fatigue: first, to balance work, rest and time off across and between duty cycles; and second, to impose limits on single duty periods that commenced very late at night and very early in the morning, which were likely to impinge on the "normal hours of sleep. ${ }^{75}$ A sliding scale of duty period length was recommended. The length of duty periods should, the Committee proposed, depend on the time of day duty began and the number of sectors flown. It advised that the limitations in Table 7.2 'should be mandatory for scheduling purposes. ${ }^{76}$ However, the Committee recommended that this basic guide should be amended in a number of different circumstances. For flights that commenced away from base, for example, the Bader Committee recommended that flying duty periods should be modified to take into account the length of the preceding rest period and possible sleeplessness following transoceanic flight.

In an attempt to balance duty cycles, the Bader Committee proposed cumulative weekly, monthly and annual limits on flying hours, in addition to control of rest periods. The Committee's report recommended that weekly duty should not exceed fifty hours, monthly flying hours should not exceed 100 hours - although duty hours could be extended to 160 , similar to the monthly hours the Bader Committee deemed 'normal' in other occupations - and set an annual limit of 900 flying hours. ${ }^{77}$ Like the framework proposed for calculating the length of flying duty periods, the Bader Committee recommended a sliding scale for rest periods, ranging from twelve to eighteen hours, during which time crew were 'required' to rest. ${ }^{78}$ Reflecting a wider contemporary discourse of therapeutic relaxation - which was 'best conducted lying down' - the Committee mandated that rest prior to flying should be at least eight hours in length, 'uninterrupted' and 'horizontal. ${ }^{\text {,9 }}$ Sleep was not a prerequisite, but was desirable.

The Bader Committee's report closed with a discussion of subsequent legislation and enforcement. It concluded that regulations should 
Table 7.2: Flying duty period commencing at 'base'. Report of the Committee on Flight Time Limitations, p. 18

\begin{tabular}{llcccccccr}
\hline & \multicolumn{8}{c}{ Maximum length of flying duty period/number of } \\
sectors & \\
& $\mathbf{1}$ & $\mathbf{2}$ & $\mathbf{3}$ & $\mathbf{4}$ & $\mathbf{5}$ & $\mathbf{6}$ & $\mathbf{7}$ & $\mathbf{8}+$ \\
\hline $\mathbf{0 8 0 1 - 1 3 0 0}$ & 14 & 13.25 & 12.5 & 11.75 & 11 & 10.25 & 9.5 & 9 \\
$\mathbf{1 3 0 1 - 1 8 0 0}$ & 13 & 12.25 & 11.5 & 10.75 & 10 & 9.25 & 9 & 9 \\
$\mathbf{1 8 0 1 - 2 2 0 0}$ & 12 & 11.25 & 10.5 & 9.75 & 9 & 9 & 9 & 9 \\
$\mathbf{2 2 0 1 - 0 6 0 0}$ & 11 & 10.25 & 9.5 & 9 & 9 & 9 & 9 & 9 \\
$\mathbf{0 6 0 1 - 0 8 0 0}$ & 12.5 & 11.75 & 11 & 9.5 & 9.5 & 9 & 9 & 9 \\
\hline
\end{tabular}

be easy to amend, given the constantly changing nature of the modern aviation industry. 'We believe', the Committee began, that a matter as 'technically complex, and in need of progressive review, as Flight Time Limitations does not lend itself to the processes involved in legislation ... We are not convinced of the need to provide rules in the form of legislation, the infringement of which renders either the individual or the operator liable to criminal proceedings. ${ }^{, 80}$ The Committee instead recommended a permissive system of control premised on voluntarism and self-regulation by industry. To this end, it proposed that subsequent regulations should be 'basic in form', so they could be applied to different circumstances. ${ }^{81}$ The Committee recommended that the existing ANO be amended to offer more flexibility, and then supplemented by detailed guidance material in a Civil Aviation Publication (CAP).

Following the publication of the Bader Committee's report in June 1973, the CAA published a detailed guidance document in 1975, The Avoidance of Excessive Fatigue in Aircrews, more commonly referred to as CAP $371 .^{82}$ This publication closely followed the recommendations of the Bader Committee. The maximum permissible flying duty hours were lifted straight from the report: fourteen hours a day, 100 hours a month and 900 hours a year. Also on the recommendation of the Bader Committee, the CAA appointed an advisory Flight Time Limitations Board (FTLB), initially led by Douglas Bader, to advise the CAA on issues of flight safety, flight time limitations and associated legislation. The main function of the FTLB was to approve or disprove variations. 
Under CAP 371 operators could submit a scheme with slight variations to the FTLB for consideration if compensatory factors meant that the overall scheme 'achieved an equivalent level of safety' to CAP $371{ }^{83}$ Though formally titled a 'requirements document', the recommendations set out in CAP 371 had no legal standing but were, rather, a code of practice similar to the British Civil Airworthiness Requirements. Under CAP 371, airlines were allowed 'reasonable freedom' to apply the recommendations of the publication with 'commonsense. ${ }^{84}$ Deliberately flexible, it was hoped that, if airlines had scope to update flight time limitations in response to new technologies or demands, CAP 371 would be applicable for years to come.

However, the 'freedom' to interpret the regulations contained in CAP 371 in a way that suited the needs of operators left it open to manipulation. ${ }^{85}$ In August 1973, shortly after the publication of its report, the Bader Committee discussed this potential problem. The Committee suspected that, particularly in the early stages of the new regulatory framework, there might be 'very large numbers of requests made for variations.'Widespread use of variations could, the Committee thought, 'debase the general level of protection' intended under CAP $371 .{ }^{86}$ The Bader Committee's initial misgivings proved correct. By 1977 over 300 variations had been granted by the CAA, many with little or no regard for compensatory factors. Low-cost operator Dan-Air, for example, reduced some flying periods by just fifteen minutes - a cursory effort given that the airline had reduced rest periods following standby from eighteen to twelve hours. ${ }^{87}$ The primary aim of CAP 371 - to balance work and rest within and between duty cycles - was undermined.

The flight time limitations introduced in 1975, then, marked a shift in principle but not in practice. Based on an understanding of fatigue as cumulative rather than acute, the 1975 limitations initiated a regulatory philosophy that attempted to balance work and rest across the duty cycle rather than limit single duty periods. But in practice, given the scope for variation and the extension of duty periods at the captain's discretion, it was still legally possible for operators to schedule imbalanced rosters. This became an increasing problem in the late 1970s, following economic deregulation and the increasing marketisation of civil aviation. ${ }^{88}$ A number of new low-cost airlines entered the market in this period. Operating within often tight profit margins, many of these airlines were more commercially motivated than the traditional 
flag carriers. Employment of pilots was one of the major costs for airlines, after aircraft and fuel, and the new low-cost operators were keen to ensure a good return. Pilot utilisation and scheduling were key concerns, and increasing competition prompted some airlines to exploit the permissive nature of CAP 371 for commercial gain. In the decade following the introduction of CAP 371 low-cost airlines and inclusive tour operators, such as Dan-Air and Monarch, frequently scheduled pilots to work the maximum number of hours possible and rostered trips 'to the absolute limit of CAP $371{ }^{\prime 89}$ Ideally, operators should have made provision for minor delays, but charter airlines and low-cost operators - which tended to prioritise profitability above health and safety concerns - rarely observed this guidance. Within ever-tighter schedules, the slightest delay necessitated the use of the captain's discretionary power to extend the duty day. ${ }^{90}$ Reminiscent of the intensive and imbalanced working practices that had first prompted regulatory intervention by the state in the 1950s, an article published in BALPA's membership magazine in 1982 claimed that the union had received 'extreme, but not infrequent' reports of pilots working for ' 24 hours or more without sleep."91

The regulatory framework introduced by the CAA in 1975 did not protect flight deck crew from intensive and imbalanced rosters as it intended. The trends begun in the late 1970s were exacerbated in the early 1980s, following revisions to CAP 371 and the introduction of a new confidential reporting service. The second edition of CAP 371, introduced in 1982, was less detailed than its previous iteration. The general principle underpinning the publication - that work, rest and time off were balanced across and between duty cycles - remained intact, but the tone of the guidelines shifted. The language of the revised publication recognised the flexible and permissive nature of the limitations. It marked a pragmatic realisation by regulatory agencies that the framework of flight time limitations introduced in 1975 was negotiable: the updated guidelines recognised the pre-existing limitations of the regulatory framework, and clarified these for airlines and crew. In the same year the CAA also established a confidential reporting service, the Confidential Human Factors Incident Reporting Programme (CHIRP). Flight deck crew were encouraged to share concerns about scheduling, fatigue and sleeplessness with CHIRP. Housed at the RAF Institute of Aviation Medicine, CHIRP was formally separate from the CAA. 
Rather than regulation, CHIRP's remit was to circulate pilots' concerns in incident reports, and provide advice on the self-management of fatigue in flight. 1982, then, marked a shift in regulatory policy. Though the framework of flight time limitations introduced in 1975 remained, pilot fatigue was reconfigured in collective terms; under the second edition of CAP 371 the avoidance of fatigue became a collective responsibility. Aircrew in the flight deck and the cabin were required to engage in collective self-regulation by reporting incidents about themselves and their colleagues to CHIRP. This updated regulatory framework echoed post-war public health approaches to disease management: pilots were framed both as individuals, but also as part of a broader collective. Tensions between individual and collective approaches to flying fatigue continued into the 1990s, but the pilot was formally repositioned in regulatory discourses following the introduction of mandatory Crew Resource Management training that emphasised the importance of crew-wide cooperation for air safety. ${ }^{92}$ To this end, at the close of the twentieth century the 'self' was - finally - decentred in civil aviation.

\section{Conclusion}

The post-war era ushered in a 'new wave of state interventionism' in some respects. ${ }^{93}$ The period is often defined as one of collective provision, with the nationalisation of industry, transport and healthcare cited as primary examples of this overarching trend. ${ }^{94}$ As political historians are increasingly recognising, though, liberal values which stressed selfreliance rather than state intervention continued to influence policy throughout the post-war period. ${ }^{95}$ The apparent shift from post-war settlement to neo-liberalism under Thatcher is an attractive but, as Peter Kerr has put it, 'ultimately misleading' picture of twentieth-century British social and economic policy. ${ }^{96}$ As this chapter has shown, even in the immediate post-war period British governments were reluctant to extend their regulatory reach, and even when regulations were introduced the state did not put statutory systems of enforcement in place.

The regulatory framework to control airline schedules shifted somewhat across the twentieth century. The state initially demanded that airlines impose some form of limitation under the 1957 ANO, but in 
the 1970s these limits were quantified (although not standardised) in CAP 371. By the 1980s the permissive nature of these regulations was formally recognised. In this period, agencies involved in regulation multiplied and their focus shifted from command-and-control regulation of aircrew schedules towards surveillance on the one hand, and the collection and dissemination of information to workers on the other. In this framework the role of the state became limited to the facilitation of self-regulation by industry.

There was no fundamental shift in the approach or impact of flight time limitations in post-war Britain. Though premised on a new understanding of fatigue as cumulative rather than acute, the regulations introduced in 1975 marked a shift in principle rather than practice. The work and rest of pilots was more strictly regulated under CAP 371 than in any other industry in post-war Britain, but the responsibility for fatigue management clearly remained with pilots and airlines rather than state agencies. Reliant on a heroic understanding of flight centred on individuals, the regulatory frameworks introduced to minimise fatigue in the twentieth century envisioned commercial pilots as autonomous agents capable of self-awareness, governance and - ultimately - balance. A trusted professional, the post-war pilot was expected to balance health, safety and commercial concerns without the need for external intervention. Fatigue collapsed the distance between economics, biology and safety. It was identified as a modern hazard with obvious implications beyond the individual in the immediate post-war period, but the potential social consequences of pilot fatigue did not come to influence the regulatory frameworks designed to minimise its effects until the close of the twentieth century. For much of the post-war period flight safety, rather, relied on a rubric of personal responsibility, self-regulation and individualism.

\section{Notes}

1 Anon., 'The Kallang Inquiry', Flight International, 19 November 1954, p. 754 .

2 The National Archives, London (hereafter TNA) BT/248/110, extract from the Kallang Accident Inquiry Report, 1954, p. 1.

3 Ibid., p. 1.

4 Anon., 'The pilot, not ridge gets blame', The Singapore Free Press, 16 November 1954, p. 1. 
5 T. C. Lawton, 'Governing the skies: conditions for the Europeanisation of airline policy’, Journal of Public Policy, 19:1 (1999), 91-112.

6 D. Follows, 'Duty hours of pilots: recommendations to minister', The Times, 20 November 1954, p. 7.

7 TNA BT 248/110, Ministry of Civil Aviation minutes, 26 November 1954, p. 19.

8 TNA BT 248/110, Report of the Working Party on Operating Crew Fatigue and Flight Time Limitations, 15 December 1954.

9 J. Terraine, The Right of the Line: The Role of the RAF in World War Two (Barnsley: Pen and Sword Military, 2010).

101954 accident report cited in TNA DR/13/4, Report of the Committee on Flight Time Limitations, June 1973, p. 42.

11 H. E. Collier, 'The recognition of fatigue, with special reference to the clinical diagnosis of morbid fatigue in industry', British Medical Journal, 2:3964 (1936), 1322-5, at p. 1323.

12 Ibid., p. 1323.

13 A. Hemingway, 'The physiological background of fatigue', in W. F. Floyd and A. T. Welford (eds), The Ergonomics Research Society Symposium on Fatigue (London: H. K. Lewis \& Company, 1953), pp. 69-75.

14 A. Abrahams, 'Chronic fatigue', Lancet, 246:6371 (1945), 421-2. For a broader history of physiological research into balance and homeostasis, see: M. Jackson, The Age of Stress: Science and the Search for Stability (Oxford: Oxford University Press, 2013); and V. Heggie, A History of British Sports Medicine (Manchester: Manchester University Press, 2013).

15 Lawton, 'Governing the skies'.

16 The focus here is on the regulation of pilots' hours of work and rest, though cabin crew were also included in the regulatory framework described in the second part of this chapter.

17 R. Hayward, 'Busman's stomach and the embodiment of modernity', Contemporary British History, 31:1 (2017), 1-23.

18 C. Sirrs, 'Accidents and apathy: the construction of the "Robens philosophy" of occupational safety and health regulation in Britain, 1961-1974', Social History of Medicine, 29:1 (2016), 66-88.

19 V. Long, The Rise and Fall of the Healthy Factory: The Politics of Industrial Health in Britain, 1914-60 (Basingstoke: Palgrave Macmillan, 2011).

20 S. Blayney, 'Industrial fatigue and the productive body: the science of work in Britain, c.1900-1918', Social History of Medicine, 32:2 (2017), 310-28.

21 A. J. McIvor, 'Manual work, technology, and industrial health, 1918-39', Medical History, 31:2 (1987), 160-89, at p. 167.

22 A. J. McIvor, 'Employers, the government, and industrial fatigue in Britain, 1890-1918', British Journal of Industrial Medicine, 44:11 (1987), 724-32; A. Rabinbach, The Human Motor: Energy, Fatigue, and the Origins of 
Modernity (Los Angeles: University of California Press, 1992); A. K. Schaffner, Exhaustion: A History (New York: Columbia University Press, 2016); Blayney, 'Industrial fatigue and the productive body'.

23 A. Derickson, Dangerously Sleepy: Overworked Americans and the Cult of Manly Wakefulness (Philadelphia: University of Pennsylvania Press, 2014).

24 B. M. Hutter, Regulation and Risk: Occupational Health and Safety on the Railways (Oxford: Oxford University Press, 2001).

25 Derickson, Dangerously Sleepy, p. 27.

26 Ibid.

27 TNA BT 248/110, Ministry of Civil Aviation minutes, 26 November 1954, p. 19.

28 TNA BT 248/110, BALPA Flight Time Limitations Memorandum, 2 December 1954; TNA BT 248/110, Ministry of Civil Aviation minutes, 21 December 1954, p. 28.

29 TNA BT 248/110, Report of the Working Party on Operating Crew Fatigue and Flight Time Limitations.

30 Ibid., p. 6.

31 TNA BT 248/110, Working Party on Operating Crew Fatigue, meetings 2 and 3 September 1954, p. 1.

32 TNA BT 248/110, Report of the Working Party on Operating Crew Fatigue and Flight Time Limitations, pp. 7-8.

33 TNA BT 248/110, Report of the Working Party on Operating Crew Fatigue and Flight Time Limitations, p. 8; Chapter 8 (this volume) also speaks to the tension between practical considerations and the health of workers in the post-war period.

34 TNA BT 248/110, BALPA Flight Time Limitations Memorandum, p. 1.

35 Ibid., p. 2.

36 TNA BT 248/110, Report of the Working Party on Operating Crew Fatigue and Flight Time Limitations, p. 6.

37 TNA BT 248/110, Working Party on Operating Crew Fatigue, meetings 2 and 3 September 1954, p. 2.

38 On contemporary debates about the practical and ethical importance of professional autonomy in medicine, see: A. Seaton, 'Against the "sacred cow": NHS opposition and the Fellowship for Freedom in Medicine, 1948-72', Twentieth Century British History, 26:3 (2015), 424-49.

39 D. Armstrong, 'Actors, patients and agency: a recent history', Sociology of Health and Illness, 36:2 (2014), 163-74.

40 C. Muller, 'The Institute of Economic Affairs: undermining the post-war consensus', Contemporary British History, 10:1 (1996), 88-110.

41 A. Gamble, 'Privatization, Thatcherism, and the British state', Journal of Law and Society, 16:1 (1989), 1-20. 
42 The idea of state intervention in industrial and economic matters was not universally popular in the immediate post-war period either. A rhetoric of planning permeated the political arena, but state intervention was subject to debate among economists, policy-makers and civil servants. For a history of post-war planning debates, see: J. Tomlinson, 'Planning: debate and policy in the 1940s', Twentieth Century British History, 3:2 (1992), 154-74; R. Toye, 'Gosplanners versus thermostatters: Whitehall planning debates and their political consequences, 1945-49', Contemporary British History, 14:4 (2000), 81-106.

43 Terraine, The Right of the Line.

44 TNA BT 248/110, Report of the Working Party on Operating Crew Fatigue and Flight Time Limitations, p. 6; TNA BT 248/110, Working Party on Operating Crew Fatigue, meetings 2 and 3 September 1954, p. 7.

45 TNA BT 248/110, Report of the Working Party on Operating Crew Fatigue and Flight Time Limitations, p. 7.

46 TNA BT 248/110, Working Party on Operating Crew Fatigue, meetings 2 and 3 September 1954, p. 8.

47 A. N. J. Blain, Pilots and Management: Industrial Relations in the UK Airlines (London: George Allen and Unwin, 1972).

48 A. T. Spooner, 'Flight time limitations', The Log, 42:5 (October 1982), $20-1$, at p. 21.

49 TNA BT 248/111, note of meeting in Berkeley Square House, 28 September 1955, p. 1 .

50 Ibid., p. 1.

51 B. Jackson, 'The think-tank archipelago: Thatcherism and neo-liberalism', in B. Jackson and R. Saunders (eds), Making Thatcher's Britain (Cambridge: Cambridge University Press, 2012), pp. 43-61.

52 Sirrs, 'Accidents and apathy'.

53 Lord Robens, Safety and Health at Work: Report of the Committee 1970-72, vol. 1, Cmnd 5034 (London: HMSO, 1972). There was widespread resistance to top-down regulation in this period, as Chapter 3 in this volume describes in relation to alcohol pricing.

54 Robens, Safety and Health at Work, p. xiv; Hutter, Regulation and Risk.

55 Blain, Pilots and Management.

56 Air Accidents Investigation Branch, Trident I G-ARPI: Report of the Public Inquiry into the Causes and Circumstances of the Accident near Staines on 18 June 1972 (London: HMSO, 1973), p. 54.

57 Anon., 'Pilot gave warning of crash risk in using inexperienced crews "two hours before Trident take-off'”, The Times, 29 November 1972.

58 TNA DR 13/4, Report of the Committee on Flight Time Limitations.

59 Ibid., p. 3. 
60 J. Aschoff, 'Circadian rhythms in man', Science, 148:3676 (1965), 1427-32, at p. 1432.

61 For a broader view of physiological research in this period, see Jackson, The Age of Stress.

62 P. J. Taylor, 'Shift and day work: a comparison of sickness absence, lateness, and other absence behaviour at an oil refinery from 1962 to 1965', British Journal of Industrial Medicine, 24:2 (1967), 93-102; R. T. W. L. Conroy, A. L. Elliot and J. N. Mills, 'Circadian rhythms in plasma concentration of 11-hydroxycorticosteroids in men working on night shift and in permanent night workers', British Journal of Industrial Medicine, 27:2 (1970), 170-4. As Chapter 8 (this volume) makes clear, circadian disruption was also studied by scientists interested in human performance in extreme environments.

63 R. A. McFarland, 'Air travel across time zones', American Scientist, 63:1 (1975), 23-30.

64 TNA DR 13/4, Report of the Committee on Flight Time Limitations, p. 8.

65 Ibid., p. 8.

66 Ibid., p. 7.

67 Ibid., p. 15.

68 Ibid., p. 15.

69 F. Cooper, 'Medical feminism, working mothers, and the limits of home: finding a balance between self-care and other-care in cross-cultural debates about health and lifestyle, 1952-1956', Palgrave Communications, 2 (2016), article 16042, available at https://doi.org/10.1057/palcomms.2016.42, accessed 14 July 2016; TNA DR 13/4, Report of the Committee on Flight Time Limitations, p. 27.

70 Chapter 8 in this volume traces a similar shift. While early investigations of human performance in extreme environments focused almost exclusively on physiological adaptation, by the 1970s research interest centred on psychological and social factors.

71 M. Young and P. Wilmott, The Symmetrical Family (London: Penguin, 1973), p. 164.

72 H. J. Freudenberger, 'Staff burn-out', Journal of Social Issues, 30:1 (1974), $159-65$.

73 TNA DR 13/4, Report of the Committee on Flight Time Limitations, p. 15.

74 This approach to working time regulation reflected the promotion of moderation in contemporary public health policy, as outlined in Chapters 3 and 4 in this volume.

75 TNA DR 13/4, Report of the Committee on Flight Time Limitations, p. 17. 
76 Ibid., p. 12

77 Ibid., p. 8.

78 Ibid., p. 15.

79 A. Nathoo, 'Initiating therapeutic relaxation in Britain: a twentieth-century strategy for health and wellbeing', Palgrave Communications, 2 (2016), article 16043, p.3, available at https://doi.org/10.1057/palcomms.2016.43, accessed 20 July 2016; TNA DR 13/4, Report of the Committee on Flight Time Limitations, p. 25.

80 TNA DR 13/4, Report of the Committee on Flight Time Limitations, p. 30.

81 Ibid., p. 26.

82 Civil Aviation Authority, CAP 371: The Avoidance of Excessive Fatigue in Aircrews Requirements Document (London: Civil Aviation Authority, 1975).

83 TNA DR 13/1, Flight Time Limitations Board, minutes of meeting, 13 November 1975, p. 1.

84 TNA DR 13/4, Report of the Committee on Flight Time Limitations, p. 32.

85 Ibid., p. 32.

86 Ibid., p. 3.

87 Ibid., p. 24.

88 For a broader history of financial deregulation and marketisation, see P. Addison, No Turning Back: The Peacetime Revolutions of Post-War Britain (Oxford: Oxford University Press, 2010).

89 R. Green and R. Skinner, 'CHIRP and fatigue', The Log, 48:5 (October 1987), 6-11, at p. 8.

90 Ibid.

91 T. Staples, 'Flight time limitations: is "up to a 14-hour day" really unacceptable?', The Log, 43:6 (1982), 19.

92 R. Flin, P. O'Connor and K. Mearns, 'Crew resource management: improving team work in high reliability industries', Team Performance Management, 8:3/4 (2002), 68-78.

93 G. Eghigian, A. Killen and C. Leuenberger, 'The self as project: politics and the human sciences in the twentieth century', Osiris, 22:1 (2007), 1-25, at p. 22.

94 Addison, No Turning Back.

95 N. Rollings, 'Cracks in the post-war Keynesian settlement? The role of organised business in Britain in the rise of neoliberalism before Margaret Thatcher', Twentieth Century British History, 24:4 (2013), 637-59.

96 P. Kerr, Postwar British Politics: From Conflict to Consensus (London: Routledge, 2001), p. 5. 
Natasha Feiner - 9781526132123

Downloaded from manchesterhive.com at 04/26/2023 01:04:12AM 